\title{
Nova democracia e formação humana: a proposta da educação ambiental ecomunitarista
}

\section{Democracy and human education. The ecommunitarianist environmental education}

\author{
SIRIO LOPEZ VELASCO ${ }^{1}$
}

\begin{abstract}
Resumo: Neste trabalho abordamos a necessidade de uma nova democracia para o Brasil, e propomos a educação ambiental ecomunitarista como modelo de formação humana capaz de sustentar essa nova ordem democrática. Partimos da constatação de que a suposta democracia representativa chegou no Brasil a uma situação de esgotamento, pelo fato de que os supostos representantes não representam os supostos representados, e pela vinda à luz de uma corrupção sistêmica que afeta quase todas as formações políticas com funções executivas ou legislativas. Esse esgotamento leva à necessidade de se construir uma nova democracia, nos moldes participativos. Para fundamentá-la propomos as três normas básicas da ética, que temos deduzido argumentativamente da gramática profunda da pergunta que a instaura, a saber 'Que devo fazer?'; assim essas normas tem validade intersubjetiva universal e são insuperáveis, pois se apóiam nos limites do pensamento discursivo. A primeira dessas normas exige que lutemos para garantir a nossa liberdade individual de decisão (entendendo que o ser humano não é livre, mas está obrigado por essa norma a lutar pela sua liberdade); a segunda norma nos obriga a realizarmos essa liberdade em buscas de respostas e ações consensuais com os outros (de forma que a nossa liberdade não se oponha a deles, mas se prolongue nela); e a terceira norma nos obriga a preservarregenerar uma natureza humana e não humana sadia. Com base nessas três normas fundamentais apresentamos um breve perfil do ecomunitarismo (ordem socioambiental utópica pós-capitalista, guia e horizonte parta a ação cotidiana) e resumimos algumas características básicas da educação ambiental ecomunitarista, base político-pedagógica da nova democracia proposta. Uma e outra devem abranger, entre outras, as esferas da educação formal e não formal, a economia ecológica e sem patrões, a política de todos e a comunicação simétrica.
\end{abstract}

Palavras-chave: Brasil. Nova democracia. Educação ambiental ecomunitarista. Ecomunitarismo.

Abstract: In this paper we approach the need of a new democracy in Brazil, and propose the ecommunitarianist environmental education like a model of human education to sustain this new democratic order. We start from the fact that the supposed representative democracy in Brazil came to a impasse because the supposed represent ants don't represent the citizens, and because a systemic corruption appear all days in the newspapers involving almost of the political organization with responsibilities at the executive or legislative level. These facts shows the necessity of a new democracy with participative fundaments. To base this new democracy we propose the three basic ethical norms that we deduced from the profound Grammar of the capital question of ethics, What must I do? These norms have a intersubjective and universal validity because them are founded at the border of argumentative discourse. The first of these norms obligate each of human beings to fight for his freedom to decide; the second one obligate us to use this freedom in consensual research of answers and actions with de others; and the third of the three basic norms of

\footnotetext{
${ }^{1}$ Filósofo e Professor Titular da FURG e Doutor em Filosofia pela Université Catholique de Louvain (1985). Atuou como Professor Visitante do PET/Filosofia da UNIOESTE. E-mail: lopesirio@hotmail.com
} 
ethics obligate us to preserve and regenerate a healthy human and non human nature. Since these three norms we present the abstract of ecommunitarianism (utopic post capitalistic political and environmental order that guide us each day in each action) and we resume some of the characteristics of the ecommunitarianist environmental education that is the pedagogic and political basis of the new democracy we propose. Both of them must include, between other dimensions, the formal and non formal education, the ecological e cooperative economy, and a symmetrical communication.

Keywords: Brazil. New democracy. Ecommunitarianist environmental education. Ecommunitarianism.

\section{Introdução}

A chamada democracia representativa, entronizada como padrão no capitalismo, está enfrentando seus limites, especialmente no Brasil. Uma das causas de tal crise é o simples fato de que em instâncias decisivas para as vidas do conjunto dos cidadãos (nas áreas da economia, da seguridade social, da saúde, da educação, etc.), os supostos representantes tomam decisões que não representam seus supostos representados (ou seja, a maioria daqueles que os votaram). Isso acontece porque tais supostos representantes de fato o são dos grandes interesses capitalistas, que através da corrupção sistêmica garantem sua fidelidade nos momentos cruciais. Essa situação nos leva a propor uma nova democracia participativa, orientada rumo ao ecomunitarismo.

Ora, desde Sócrates, a democracia sofre a crítica de que os cidadãos chamados a decidirem em pé de igualdade não têm o conhecimento-educação adequados para assumirem com rigor e competência essa função. Para suprir essa carência propomos o paradigma da educação ambiental ecomunitarista (tanto na educação formal quanto na educação não formal).

\section{Impasse e alternativa para a democracia no Brasil}

Nas eleições municipais de 2016 foi muito significativo o aumento em todo o país da abstenção, do voto nulo e dos votos brancos, quando se compara os resultados com as mesmas eleições de 2012. Houve casos (como ocorreu em Porto Alegre) em que o número absoluto de pessoas que optaram por uma dessas três alternativas foi superior ao número de votos recolhido pelo candidato vencedor no segundo turno. Ao nosso entender, esses dados demonstram um claro protesto dos eleitores contra a classe política brasileira e contra a própria estruturafuncionamento da suposta democracia representativa atual no Brasil. Isto nos leva a lembrar que, em março de 2016, saíram à luz as chamadas "listas da Odebrecht" (uma das grandes empreiteiras responsáveis, junto com outras grandes empresas e atores políticos e seus respectivos indicados, por bilionários roubos e corrupção às custas do dinheiro público) que mostravam que essa empresa tinha realizado 
"doações" a políticos de nada menos do que 24 Partidos (desde os da suposta esquerda, tanto no Governo Federal, a começar pelo PT, até aquela da oposição, quanto de toda a direita, tanto a coligada com o PT a nível federal, quanto aquela da oposição), e que as apurações então feitas autorizavam o cidadão a imaginar que inclusive por trás das chamadas "doações legais" se escondiam casos de suborno (atual ou potencial).

Diante dessa situação e do fato de que boa parte da cidadania parecia estar cansada "dos políticos" em geral, fazíamos uma pergunta que agora reiteramos: por que, numa perspectiva do socialismo de inspiração ecomunitarista, não levantar a bandeira de uma nova e efetiva democracia no Brasil, nos moldes de uma democracia participativa? Essa democracia, fundamentada nas três normas éticas básicas que nos exigem lutarmos para garantir a nossa liberdade individual de decisão, exercer essa liberdade em buscas de consensos com os outros (possíveis plenamente numa sociedade sem classes), e preservar-regenerar a saúde da natureza humana e não-humana, deveria partir de Assembléias Constituintes (com representantes eleitos diretamente pela cidadania para sua função) a nível federal e de cada Estado, para redigir novas Cartas Magnas, que seriam depois submetidas a plebiscitos.

No plano político, essa democracia privilegiaria a democracia direta (mantendo o mínimo indispensável de funções representativas, de representantes que seriam revogáveis em referendos revogatórios por parte dos eleitores de cada nível), exercida presencialmente e/ou com a ajuda dos mecanismos informáticos (internet) a partir do nível local (do bairro, o distrito e o município) até o plano nacional, para que o cidadão (como acontecia na Atenas inventora da democracia) realmente decida sobre as grandes questões que afetam a sua vida (orçamento, impostos, escala salarial, aposentadorias, jornada de trabalho, meio ambiente, educação, saúde, moradia, segurança, defesa, política internacional, etc.).

A nível econômico, essa democracia supõe a caminhada rumo a uma economia ecológica e sem patrões, que funcione em base a uma esfera de meios socializados diretamente (articulado em base a verdadeiras cooperativas), outra de meios estatais sob controle popular, e outra privada (nas áreas que não sejam consideradas estratégicas, e restritas à pequena e média propriedade rural e urbana, uma vez que os latifúndios serão abolidos através de uma profunda reforma agrária que coloque a terra em mãos dos produtores diretos associados solidariamente, para trabalharem na agricultura orgânica); na área da moradia essa democracia caminhará rumo à extinção das favelas reassentando a população favelada em bairros dignos situados em zonas que não sejam de risco, e sem colocar em risco os mananciais e outros recursos naturais indispensáveis; essa política visaria acabar com as atuais megacidades (nas quais reina a pobreza, o consumo de drogas e a violência) para reassentar voluntariamente quem quisesse no campo ou em cidades pequenas ou 
médias com muitos espaços verdes e com produção de alimentos orgânicos; na área das energias essa economia privilegiará as limpas e renováveis (como a eólica e a solar, que não causam graves transtornos aos ecossistemas e às populações como acontece com a hidráulica), ao tempo em que educará para o consumo baseado na frugalidade ecológica, recusando o supérfluo, e reduzindo, reutilizando e reciclando os recursos utilizados e os resíduos gerados; na esfera dos transportes essa economia democrática privilegiará os coletivos, freqüentes, rápidos e limpos (também na energia por eles usada).

$\mathrm{Na}$ área da saúde, essa democracia criará um verdadeiro sistema único, universal, gratuito e eficiente/rápido, atendido com pessoal especializado e bem remunerado, auxiliado pela mais avançada tecnologia e os melhores conhecimentos tradicionais e não tradicionais (para privilegiar a saúde integral alicerçada na prevenção, pela prática dos bons estilos de vida).

$\mathrm{Na}$ esfera comunicacional essa democracia supõe a abolição dos atuais latifúndios midiáticos e a divisão em três terços iguais das mídias comunitárias/cooperativas, públicas e privadas (impedindo-se a estas últimas a configuração de monopólios e oligopólios nacionais, regionais ou locais).

Na esfera educativa formal e não formal, essa democracia supõe a adoção da pedagogia problematizadora nos moldes da educação ambiental ecomunitarista, oposta ao racismo, e que inclui também a erótica da libertação e a educação sexual emancipadora (que combate o machismo e a homofobia, e prega o livre desfrute do prazer consensuado que não violente a liberdade dos parceiros nem diminua a sua saúde, conforme o exigem as três normas éticas básicas); essa educação incentivará o cultivo de um corpo saudável em harmonia com uma mente saudável, promovendo a educação física formadora e o esporte educativo e cooperativo (e deixará para atrás o esporte-negócio, usuário de drogas, e individualista/estrelista do capitalismo); essa educação também promoverá a formação artística, que inclui tanto o cultivo para o livre e gratuito desfrute estético da natureza e das obras humanas, quanto a criação de obras com vocação estética por parte de todas e cada uma das pessoas.

$\mathrm{Na}$ área da segurança, essa democracia apoiar-se-á na atividade coletiva preventiva-de-vigilância da vizinhança em cada bairro e localidade, a qual se complementará com os corpos especializados que se revelarem indispensáveis.

Na área da defesa, essa democracia apoiar-se-á nas milícias populares (ao estilo ateniense) que serão complementadas pelos corpos especializados que se revelarem indispensáveis.

A nível internacional, essa democracia buscaria se articular com outras similares na A. Latina, visando a construção de uma Pátria Grande solidária, independente de qualquer poder imperial ou potência estrangeira, com voz própria 
no cenário mundial (no qual apregoará e praticará a ajuda recíproca solidária e a paz permanente entre os povos).

Na vida, em geral, essa democracia promoverá a realização do princípio "de cada um segundo a sua capacidade, e a cada um segundo a sua necessidade, respeitando-se os equilíbrios ecológicos”, para o desenvolvimento de indivíduos universais felizes e reconciliados com os outros e com a natureza não humana (que cuidarão e desfrutarão com fruição estética cultivada).

\section{As três normas fundamentais da ética}

Considero que a ética é o conjunto de respostas argumentadas que damos à pergunta “Que devo fazer?” na forma de Quase-raciocínios Causais (QRC). Um QRC está constituído por um obrigativo (com a forma "devo fazer tal coisa", ou "não devo fazer tal coisa", seguido do operador não veritativo "porque", seguido por sua vez de um enunciado (no sentido da lógica clássica, isto é uma sentença suscetível de ser verdadeira ou falsa). A gramática dos QRC se apresenta como segue: se resultar falseado o enunciado que sustenta o obrigativo, então essa obrigação vê-se revogada por via argumentativa (isto é, não obriga mais); terá que ser procurada outra, que seja sustentável pero mesmo ou por outro enunciado constitutivo do respectivo QRC. Se o enunciado do QRC não é falseado no debate de argumentos, então o obrigativo permanece como obrigação legítima (até que eventualmente sua falência ocorra em novos debates). A única restrição dentro deste jogo gramatical consiste no fato de que o

[...] enunciado que sustenta o obrigativo tem que tratar do mesmo assunto (conteúdo) que este último; assim por exemplo "Devo cuidar as crianças por que o sol é uma estrela" não pode ser aceito como um QRC bem constituído. Para a dedução das normas ética é fundamental o operador lógico que chamo de condicional (e que funciona em expressões do tipo "tal coisa é condição de tal outra coisa"). A dedução dessas normas, no que constitui a fundamentação última da ética tout court, dá-se pela elucidação das condições de felicidade (no sentido de John L. Austin 1962) da pergunta que instaura a ética, a saber "Que devo fazer?" (sem ou fora da qual simplesmente não há ética) e com a ajuda do operador lógico de "condicional" (ver LOPEZ VELASCO, 2003a).

Essas três normas se apresentam resumidamente como segue (ver a dedução detalhada e as questões técnicas em LOPEZ VELASCO 2003a e 2003b).

A primeira norma me obriga a lutar para garantir a minha liberdade individual de decisão.

A segunda norma me obriga a vivenciar essa liberdade em buscas de respostasações consensuais com os outros (de forma que minha liberdade de decidir não se oponha à deles, mas se prolongue nela). 
E a terceira norma me obriga a preservar uma natureza humana e não humana sadia.

\section{O ecomunitarismo: brevíssima apresentação}

Chamo de "Ecomunitarismo" a ordem socioambiental utópica pós-capitalista (talvez nunca alcançável, mas indispensável horizonte guia da ação) capaz de se articular com base nas três normas básicas da ética e de manter-se pela postura de seres humanos em atitude de libertação; dela fazem parte: a) uma economia ecológica e solidária sem patrões, sem dinheiro e sem desemprego que preservaregenera a saúde da natureza humana e não humana e articula-se com base no princípio 'de cada um segundo sua capacidade e a cada um segundo suas necessidades' (ver sobre a extensão e legitimidade das 'necessidades" Lopez Velasco 2003b, p. 86-88), b) uma erótica do prazer compartilhado, não sexista e não repressiva (Lopez Velasco 2003b, p. 201-210), c) uma pedagogia ambiental problematizadora concretizada na educação ambiental ecomunitarista(Lopez Velasco 2003b, p. 125-129 e 210-237), d) uma política de todos (Lopez Velasco 2003b, p. 238-278), e, e) uma comunicação livre e simétrica baseada na mídia comunitária associativa, expropriando as oligarquias do seu monopólio mediático (Lopez Velasco 2009c).

Na seção intitulada "Ucronia mínima” num dos nossos livros (Lopez Velasco 2012, p. 159-194) tentamos mostrar como funcionaria uma sociedade ecomunitarista no seu dia a dia, incluindo as esferas da educação, da livre sexualidade, da economia ecológica e solidária, da política participativa direta, e da comunicação livre, democrática e simétrica.

Num primeiro relato, intitulado "Uma jornada de Almotasim em Tlön”, apresentamos um dia qualquer na vida de um casal que tem dois filhos, mostrando o funcionamento de uma economia ecológica e solidária sem patrões, o uso de energias limpas e renováveis, os relacionamentos humanos marcados pela amizade, a cooperação e o respeito mútuo, e a livre sexualidade, assim como pela prática da educação problematizadora.

Num segundo relato, intitulado "Vivendo, produzindo, distribuindo e consumindo", apresento uma oikonomia sem patrões baseada no principio "de cada um segundo suas capacidades e a cada um segundo suas necessidades" e respeitosa da preservação-regeneração da saúde da natureza humana e não humana, incluindo os problemas e dilemas de algumas pessoas que dela participam (já que o ecomunitarismo não acaba com todos os dilemas humanos, mas ajuda a enfrentá-los melhor). 
Num terceiro relato, intitulado "A escola ecomunitarista" descrevo o funcionamento da escola no ecomunitarismo, incluindo considerações relativas às instalações, às metodologias e à educação sexual.

Um quarto relato, intitulado "O amor libertário" detalha as diversas vivências da livre sexualidade prazerosa e a diversa conformação dos núcleos familiares.

O quinto relato, “A comunicação simétrica”, apresenta uma comunicação baseada em mídias comunitárias e participativas, que abrangem desde o espaço local até o planeta por inteiro. O sexto relato, "A política de todos", descreve o funcionamento concreto de uma democracia direta, participativa e decisória, que administra desde as questões locais até as planetárias. Em fim, um último relato, intitulado "Para além da Terra", mostra os seres humanos vivendo no ecomunitarismo fora da terra, inclusive depois da destruição do nosso planeta azul. A proposta ecomunitarista (incluindo a sua constituinte pedagógico-ambiental) sente-se hoje bem acompanhada por algumas idéias do ecossocialismo (ver Lopez Velasco 2003b), do ecofeminismo (ver Lopez Velasco 2003), do ecologismo dos pobres (ver Lopez Velasco 2003b), do biorregionalismo de esquerda (ver Lopez Velasco 2003b) e do socialismo do século XXI, que começa a nascer na América Latina (ver Lopez Velasco 2009b, 2010 e 2012).

\section{Ética ecomunitarista e formação (política) humana: breves considerações}

Neste ponto, nos contentamos com dizer que enxergamos a educação como fenômeno político-pedagógico, nos moldes da educação problematizadora (tanto em nível formal como no informal), segundo a ótica freireana (FREIRE, 1970), que ampliamos na nossa proposta ecomunitarista com visão sócio-ambiental no paradigma da educação ambiental. Sustento que a educação ambiental profunda é uma educação socioambiental problematizadora alicerçada nas três normas fundamentais da ética e orientada rumo ao ecomunitarismo.

Lembremos que a educação problematizadora, segundo Paulo Freire (1970), se alicerça na "conscientização", definida como a combinação do desvelamento crítico da realidade e a ação transformadora sobre ela rumo a uma sociedade sem opressores nem oprimidos. Salientamos este último elemento da concepção freireana, para mostrar que se o capitalismo comporta relações de opressão, então a educação problematizadora (se pretende ser verdadeiramente freireana) deve apontar para além do capitalismo. E o desvelamento crítico que ela deve propiciar é aquele das dominações existentes entre os seres humanos (e acrescentamos na nossa visão ecomunitarista, das relações de devastação e/ou, contaminação irreversível, existentes entre os seres humanos e a natureza não humana). Para Freire ambas facetas da educação problematizadora se dão de forma dialógica entre os oprimidos e os que assumirem a sua causa, para derrotar os opressores e a opressão (ou seja para que os atuais oprimidos não virem novos opressores). A 
fundamentação de tal educação problematizadora encontra-se nas três normas fundamentais da ética.

\section{A Educação Ambiental e a crítica do capitalismo}

O "capital” é (como Marx o definiu em "O Capital”) uma relação social, e não uma coisa (embora ele apareça sob a forma de "coisas" como o são uma certa quantia de dinheiro ou de bens móveis e imóveis, ou ainda, como capital variável, na soma do salário do trabalhador empregado por um capitalista); essa relação social é aquela que existe entre os donos dos meios de produção (dentre os quais figura a própria terra, convertida em propriedade privada de alguns) e aquela grande maioria que por não possuí-los vê-se obrigada a trabalhar para os primeiros na condição de trabalhador assalariado.

Assim percebe-se que pela sua própria definição a relação social de "capital" é desigual, e coloca uns (os trabalhadores) submetidos às ordens de outros (os capitalistas); note-se que é o capitalista quem decide se o trabalhador trabalhará ou não (por isso o desemprego é inerente ao capitalismo, já que quem quer trabalhar não é quem decide sobre se o fará ou não), e uma vez que o trabalhador conseguiu vender sua força de trabalho a um capitalista (isto é, conseguiu um emprego) é esse capitalista quem dirá o que e como o trabalhador aplicará suas aptidões produtivas (tolhendo as suas vocações múltiplas para autorizar só aquelas que sirvam à atividade que dará lucro ao capitalista), é esse capitalista quem se apropriará do produto do trabalho, embolsando o seu valor após a venda (pois o trabalhador se limita a receber, no melhor dos casos, o equivalente ao valor da sua força de trabalho).

Nessas condições, o capitalista não se importa em sacrificar a saúde do trabalhador; hoje são conhecidas as cifras assustadoras de mortos por causa da miséria do desemprego ou do sub-emprego, dos acidentes de trabalho, das doenças profissionais mortais, e dos suicídios, assim como se conhecem os números impressionantes das doenças físicas (em especial as Lesões por Esforços Repetitivos, LER) e psicossomáticas (que provocam entre outros depressão, insônia, impotência ou indiferença sexual, ou ainda o aumento excessivo da agressividade-violência no comportamento), derivadas do desemprego ou do medo do desemprego, das cadências infernais em vigor na produção, ou da exacerbação da concorrência entre os indivíduos e da cobrança em relação a cada um deles.

Assim, o capitalismo é de fato o sistema da guerra de todos contra todos entre os seres humanos, e da indiferença crescente entre eles; essa guerra afeta tanto as relações dos capitalistas com os trabalhadores, quanto as relações existentes no interior dessas duas grandes classes sociais. O capitalismo é o modo de produção no qual a produção tem por objetivo o lucro (ou seja a transformação de uma certa soma de dinheiro numa soma maior), tendo a mercadoria (incluída a força de 
trabalho assalariada) como uma simples mediação para fazer possível esse aumento do dinheiro; assim o capital realiza o ciclo D - M - D', onde M é a mercadoria, e D' é maior que D. Note-se que essa lógica que comporta uma implacável concorrência pela venda com lucro ao menor preço possível, se impõe à suposta liberdade que teria o capitalista nas suas decisões. Nessa dinâmica, sacrifica-se também, na devastação e na contaminação irreversível a saúde da natureza não humana (a qual fornece os materiais que funcionam como objeto de produção, parte do instrumento de produção, e parte do produto destinado à venda).

Assim, constatamos que o capitalismo violenta no seu dia a dia as três normas fundamentais da ética, porque ele nega a liberdade de decisão dos indivíduos (em especial dos trabalhadores, mas também dos capitalistas), porque ele não permite aos trabalhadores a participação nas decisões sobre o que fazer (já que eles devem se submeter às ordens do capitalista se quiserem manter o emprego e com ele sua renda de sobrevivência), e porque ele sacrifica a saúde, tanto dos humanos quanto da natureza não humana (porque o seu "tempo" de produção-lucro, incessantemente encurtado pela concorrência, é inferior ao tempo de recuperaçãoregeneração necessitados pelo trabalhador e pela natureza não humana, usada sem cuidado como se fosse um recurso sem fim e infinitamente renovável).

Por tudo isso, fica claro que a Educação Ambiental (EA) deve ser educação política crítica do capitalismo e defender uma ordem socioambiental que supere as mazelas deste; quando digo educação política uso o termo no seu sentido mais amplo, ou seja, refiro-me a uma educação para a formação de cidadãos capazes de organizar mediante sua participação argumentada, consciente e permanente, a polis, local, regional e planetária, na qual vivem. Tal educação, fundamentada nas três normas básicas da ética, e orientada rumo ao ecomunitarismo, deve perpassar o dia a dia das salas de aula e se estender a todas as esferas da educação da educação não formal. Para a educação formal propus as seguintes diretrizes:

1) Vincular os conteúdos a problemas socioambientais da vida dos alunos e dos brasileiros em uma ou mais das diversas áreas marcantes (que vão desde a distribuição dos meios de produção e da riqueza até a contaminação e devastação de terras águas e ar, passando pelo desemprego, a saúde e a segurança), reservando espaços para discutir essas questões sem medo de se afastar do "conteúdo específico".

2) Promover a pesquisa coletiva e individual, devendo o professor exercer o papel de "auxiliar de planejamento, observação, elaboração de hipóteses, testes das mesmas e elaboração de resultados" numa atividade que visa a "redescoberta" - "reconstrução" dos conhecimentos mediante a reflexão dialogada.

3) Sair para trabalhos de campo e/ou criar espaços, mesmo que modestos, na própria escola ou instituição educativa, voltados para atividades de pesquisa 
descritiva ou experimental. 4) Dialogar na escola (instituição educativa) e/ou "in loco" com conhecedores do tema em estudo, visando à integração entre os conhecimentos "técnicos" e as suas implicações sócio-humanas. 5) A partir do trabalho coletivo e das sistematizações elaboradas com a ajuda do professor e de conhecedores, promover ações voltadas para a informação e a busca de soluções para problemas sócio-ambientais existentes na escola ou instituição educativa, no bairro desta, no bairro de residência dos alunos e/ou na comunidade onde for realizada a pesquisa (cfr. Lopez Velasco 2008).

É obvio que eu penso que para que a proposta educativa seja um verdadeiro processo de formação política, a aplicação dessas diretrizes devem se dar numa dinâmica de permanente crítico ao capitalismo (com base nas três normas fundamentais da ética) e de defesa da alternativa ecomunitarista; (eis uma diferença capital com outras propostas educativas que se apresentam como sendo "transformadoras" ou, inclusive, como "libertadoras" ou "emancipadoras").

\section{A EA ecomunitarista: brevíssima apresentação}

A EA ecomunitarista critica o capitalismo e anuncia e ajuda a construir a ordem sócio-ambiental que haverá de superá-lo, o ecomunitarismo. Nele, a natureza não humana é desprivatizada, ou seja, colocada sob a administração da comunidade humana (desde o nível local até o nível planetário), e a produção, a distribuição e o consumo são organizados para que, a partir do esforço produtivo de todos os que estiverem em condições de produzir, mas com ocupações rotativas e sem desemprego e sem patrões, se cumpra o lema que reza "de cada um segundo suas capacidades, e a cada um segundo suas necessidades"; isto é, para que cada indivíduo possa se realizar como indivíduo universal, desenvolvendo suas múltiplas vocações e cultivando sua saúde integral.

Nessa ordem produtiva-distributiva-de-consumo que supera a era das sociedades humanas divididas em classes, as "necessidades" haverão de ser redefinidas consensualmente com base nas três normas da ética, o que inclui uma atitude humana de constante preservação e regeneração da natureza não humana, conforme o exige a terceira norma. Assim, a economia ecomunitarista é ecológica e solidária, e instrumento da realização efetiva do gênero humano, constituído como família humana real a nível planetário.

Mas simultaneamente com a economia ecológica, o ecomunitarismo pratica a democracia participativa e direta, superando a pseudo-democracia representativa (na qual de fato os supostos "representantes" não representam os supostos representados e onde primam hoje o interesses das grandes multinacionais e dos ricos do campo e da cidade, fora ou para além de qualquer processo eletivo); essa democracia participativa têm caráter resolutivo desde o nível local (por exemplo nos Conselhos Comunais, que já operam na Venezuela), e com a ajuda da Internet 
abrange espaços cada vez maiores de decisão à distância, para culminar nas questões mundiais (como o são a mudança climática, a administração comunitária e responsável dos recursos naturais renováveis e não renováveis, o plano mundial de produção, distribuição e consumo, etc.).

Acompanhando a economia ecológica e solidária e a democracia participativa, direta e resolutiva, haverá de se desenvolver a livre comunicação simétrica; ela implica a reapropriação pelas comunidades da grande mídia atual, monopolizada por uns poucos, que elaboram e distribuem diariamente o discurso único que garante a sua dominação; conjuntamente com a grande mídia socializada, haverão de funcionar as pequenas mídias comunitárias (a partir dos espaços locais, tanto para a radio e a TV) como os espaços das comunicações inter-individuais possibilitados pelo uso universalizado dos recursos eletrônicos (Internet, telefones celulares, etc.); nesse contexto a comunicação física ocorrerá através de meios públicos de transporte construídos a base de material reciclável e usando fontes de energia renováveis e limpas (como a energia solar e a eólica).

Toda essa revolução pós-capitalista está apoiada numa educação ambiental ecomunitarista que se desenvolve tanto a nível formal como a nível não formal, cobrindo a sociedade inteira através de múltiplas redes; essa educação integra uma educação sexual baseada na erótica da libertação, a qual, apoiada nas três normas da ética, apregoa a superação do machismo, da homofobia, e da condena à masturbação, e defende o livre gozo compartilhado do prazer sexual entre adultos; esse gozo supõe a superação de todo relacionamento que use a violência, as drogas que impedem o livre discernimento, e, ainda, opõe-se ao uso de menores ou de animais como parceiros sexuais (pois estes não dispõem efetivamente da livre capacidade de escolha).

Nessa sociedade de livre e responsável desfrute do prazer, floresce o erotismo, e não sobra espaço para a pobre pornografia, tão pobre humanamente que nos filmes que a veiculam os seres humanos mal falam; seres humanos que, aliás, não passam de outros tantos trabalhadores assalariados que, nesse filmes se prostituem em troca de uma soma de dinheiro para sobreviverem; note-se que a esse respeito aqueles que defendem o status de trabalhador assalariado para a prostituta e o garoto de programa, confessam sem querer essa grande verdade do capitalismo, pois dizendo que $a=b$ estamos afirmando que $b=a$, ou seja que se toda prostituta ou garoto de programa é um trabalhador assalariado, isso significa que todo trabalhador assalariado na sociedade capitalista é uma prostituta ou garoto de programa, vendendo a outrem o controle do seu corpo por algumas horas, em troca da obtenção de uma certa soma de dinheiro.

Nessa EA ecomunitarista, cada instituição educativa faz parte efetiva da comunidade na qual está inserida, tendo a comunidade como uma permanente cogerente da sua ação educativa, ao tempo em que a instituição ajuda a comunidade 
no dia a dia na construção e correção do ecomunitarismo; essa inserção local se articula com a inserção regional, continental e planetária, requeridas para a efetivação do gênero humano no ecomunitarismo.

\section{Referências}

AUSTIN, J. How to do things with words. London: Clarendon Press, 1962.

FREIRE, P. Ação cultural para a liberdade. Rio de Janeiro: Paz e Terra, 1982.

FREIRE, P. Pedagogia do oprimido. Rio de Janeiro: Paz e Terra, 1970.

ISRAEL, M. J \& LOPEZ VELASCO, S. Confieso que sigo soñando. Montevideo, Ed. Baltgráfica, 2014.

LOPEZ VELASCO, S. Fundamentos lógico-lingüísticos da ética argumentativa. São Leopoldo, RS: Nova Harmonia, 2003a. $2003 \mathrm{~b}$.

Ética para o século XXI: rumo ao ecomunitarismo. São Leopoldo, RS: Unisinos,

. Ética para mis hijos y no iniciados. Barcelona: Anthropos, 2003c.

. Introdução à Educação Ambiental Ecomunitarista. Rio Grande, RS: Ed. FURG, 2008. . Ética ecomunitarista. México: Ed. UASLP, 2009a.

. Ecomunitarismo, socialismo del siglo XXI e interculturalidad. Caracas: Ed. El Perro y

la Rana/Ministerio del PP para la Cultura, 2009b.

. Ucronía. Rio Grande, Ed. FURG, 2009c.

. El socialismo del siglo XXI en perspectiva ecomunitarista. San Luis Potosí: Ed.

UASLP, 2010.

FURG, 2012.

O socialismo do século XXI com visão marxiana-ecomunitarista. Rio Grande: Ed.

MARX, K. Das Kapital [3 vols.]. Frankfurt-Berlin: Ullstein, 1969.

Submissão: 15. 12. 2017 / Aceite: 10. 01. 2018. 